NOTE

\title{
Asian strain of Batrachochytrium dendrobatidis is widespread in the Western Ghats, India
}

\author{
Sanjay Molur ${ }^{1,2,3}$, Keerthi Krutha ${ }^{2}$, Mandar S. Paingankar ${ }^{1,4}$, Neelesh Dahanukar ${ }^{1,5, *}$ \\ ${ }^{1}$ Systematics, Ecology and Conservation Laboratory, Zoo Outreach Organization, Coimbatore, India \\ ${ }^{2}$ Field Research Division, Wildlife Information Liaison Development, Coimbatore, India \\ ${ }^{3}$ Conservation Breeding Specialist Group South Asia, Coimbatore, India \\ ${ }^{4}$ Department of Zoology, University of Pune, Pune, India \\ ${ }^{5}$ Indian Institute of Science Education and Research, Pune, India
}

\begin{abstract}
We investigated the distribution of Batrachochytrium dendrobatidis $(B d)$ fungal infections in amphibians of the Western Ghats mountain range in India, based on data from 497 samples. Eight individuals were positive, with genomic equivalents ranging from 2 to 785 zoospores. A single widespread $B d$ strain identical to the haplotype endemic to Asia was isolated. Our findings suggest that chytridiomycosis is widespread among the endemic and threatened amphibians of the entire stretch of the Western Ghats. An ecological niche-based prediction model based on all $B d$-positive reports from the Western Ghats to date suggested a higher probability of infection in the central Western Ghats of Karnataka and northern Kerala states, which host a rich diversity of endemic and threatened amphibians.
\end{abstract}

KEY WORDS: Endemic amphibians - Threatened amphibians $\cdot$ Conservation $\cdot$ Niche modeling Resale or republication not permitted without written consent of the publisher

\section{INTRODUCTION AND METHODS}

Infection caused by the chytrid fungus Batrachochytrium dendrobatidis $(B d)$ has impacted amphibian populations worldwide, leading to declines, extirpations, and even extinctions (Fisher et al. 2012, Soto-Azat et al. 2013). Studies on Bd within Asia are relatively recent (Swei et al. 2011), with under-represented data from several biodiversity-rich regions. Among these areas is the Western Ghats-Sri Lanka biodiversity hotspot, which despite having high levels of endemic and threatened amphibians, has not been surveyed extensively for diseases (Molur 2008, Stuart et al. 2008). The first report of $B d$ in amphibians of the Western Ghats was based on a single individual Indirana brachytarsus from southern parts (Nair et al. 2011) followed by a report of $8 B d$-positive samples from 3 different species sampled in the northern parts (Dahanukar et al. 2013). In the present study, we screened amphibians opportunistically throughout the entire range of the Western Ghats to understand the $B d$ distribution and host amphibian species using diagnostic nested PCR, qPCR, and DNA sequencing. Our investigation suggests that $B d$ infection is low but widespread in the Western Ghats and is detected only in endemic anurans.

We conducted the study across the Western Ghats at 36 locations (Fig. 1a) and collected 327 swab samples following a non-invasive protocol (Skerratt et al. 2008, Dahanukar et al. 2013), from June 2012 until June 2013 (see Table 1 for a list of genera sampled). Sanitization protocols were followed during field sampling (Skerratt et al. 2008, Dahanukar et al. 2013). A total of 170 voucher specimens preserved in 
(a)

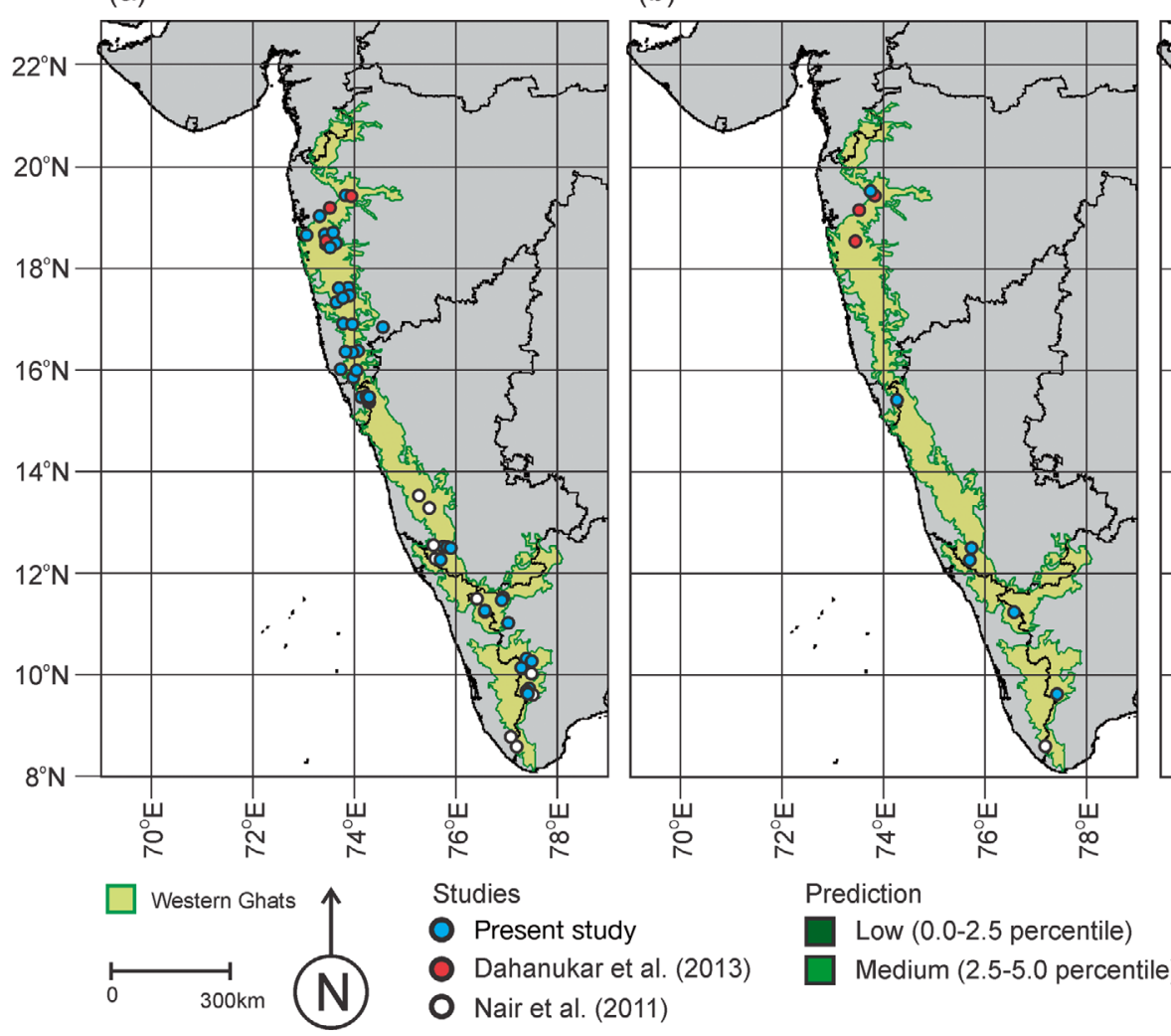

(c)

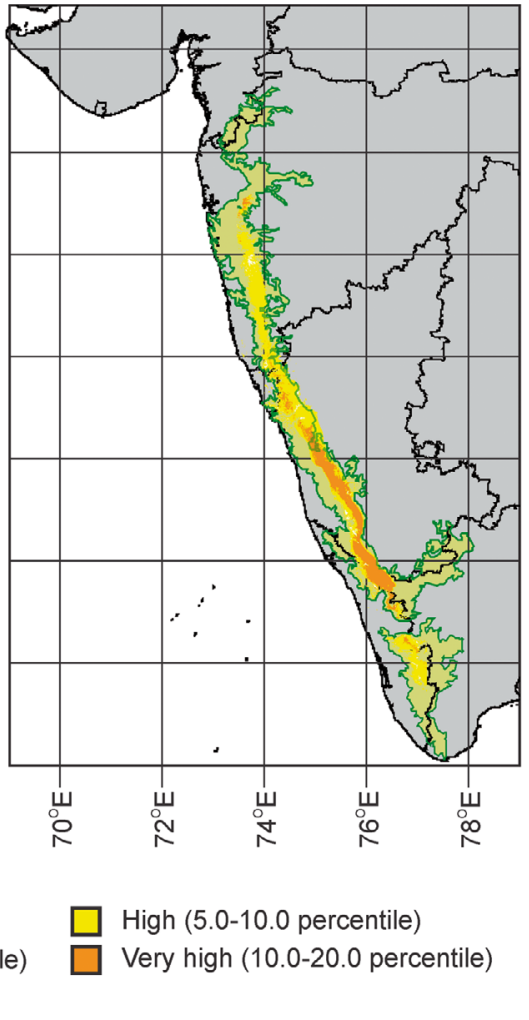

Fig. 1. (a) Sampling locations, (b) positive samples, and (c) prediction map for chytrid fungal spread in the Western Ghats, India

absolute alcohol, including museum specimens, collected between 2005 and 2013 were also tested. Additional data on $B d$-positive amphibians from the Western Ghats were retrieved from Nair et al. (2011) and Dahanukar et al. (2013).

We extracted fungal DNA from swabs following Goka et al. (2009) with modifications (Dahanukar et al. 2013), and skin and toe samples following Padhye et al. (2013). We used nested PCR technique for $B d$ specific ITS1-5.8S-ITS2 ribosomal gene sequences for PCR amplification and tested each sample twice. The first PCR was performed simultaneously, once using the primer pair ITS1f and ITS4 and once using Bd18S and Bd28S (Goka et al. 2009, Bai et al. 2010). Products of the first PCR were used for the nested PCR using the primer pair Bd1a and Bd2a (Goka et al. 2009). A 4TOPO plasmid containing a $B d$ insert of $231 \mathrm{bp}$ was used as a positive control for the second PCR. Four positive PCR products were purified and sequenced using a BigDye Terminator sequencing kit and ABI prism 3730 sequencer (Applied Biosystems). These sequences have been deposited in GenBank under accession numbers KJ533316 to KJ533319. Sequences were analyzed by BLAST (Altschul et al. 1990). Quantitative PCR based on the SYBR Green method was carried out using the primer pair ITS1-3 Chytr and 5.8S Chytr (Boyle et al. 2004) following the protocol described by Dahanukar et al. (2013). All samples were run in duplicate. Species identification of the host amphibian of the $B d$ positive samples was confirmed using 16S rDNA sequencing (Padhye et al. 2013) from buccal swabs collected alongside skin swabs.

Based on the $B d$-positive samples in the present study and earlier reports by Dahanukar et al. (2013) and Nair et al. (2011), we performed predictive nichebased distribution modeling to understand the possible regions within the Western Ghats for high $B d$ prevalence. Predictive modeling was performed in DIVA-GIS (www.diva-gis.org/) using 30 arc-second data for altitude and 19 bioclimatic parameters (Hijmans et al. 2005).

\section{RESULTS AND DISCUSSION}

In the present study, 8 out of a total of 497 samples were positive for $B d$, indicating a $B d$ occurrence rate of $1.6 \%$ (Table 1). Together with the previous studies by Nair et al. (2011) and Dahanukar et al. (2013), to date there have been $17 \mathrm{Bd}$-positive reports out of a total of 709 samples (Table 1), making the occurrence 
Table 1. Amphibian families and genera sampled in the Western Ghats, India, and numbers of Batrachochytrium dendrobatidis positive samples

\begin{tabular}{|c|c|c|c|c|c|c|c|}
\hline \multirow[t]{2}{*}{ Family } & \multirow[t]{2}{*}{ Genus } & \multirow{2}{*}{\multicolumn{2}{|c|}{$\begin{array}{c}\text { Present study } \\
\text { Samples Positives }\end{array}$}} & \multicolumn{2}{|c|}{ Dahanukar et al. (2013) } & \multicolumn{2}{|c|}{ Nair et al. (2011) } \\
\hline & & & & Samples & Positives & Samples & Positives \\
\hline \multirow[t]{2}{*}{ Bufonidae } & Duttaphrynus & 7 & 0 & 0 & 0 & 0 & 0 \\
\hline & Xanthophryne & 10 & 0 & 0 & 0 & 0 & 0 \\
\hline \multirow[t]{5}{*}{ Dicroglossidae } & Zakerana & 95 & 0 & 1 & 0 & 30 & 0 \\
\hline & Euphlyctis & 25 & 0 & 1 & 0 & 0 & 0 \\
\hline & Hoplobatrachus & 9 & 0 & 0 & 0 & 0 & 0 \\
\hline & Minervarya & 35 & 0 & 0 & 0 & 0 & 0 \\
\hline & Spherotheca & 2 & 0 & 0 & 0 & 0 & 0 \\
\hline \multirow[t]{5}{*}{ Rhacophoridae } & Polypedates & 3 & 0 & 0 & 0 & 0 & 0 \\
\hline & Rhacophorus & 7 & 0 & 0 & 0 & 0 & 0 \\
\hline & Raorchestes & 70 & 2 & 3 & 1 & 0 & 0 \\
\hline & Pseudophilautus & 18 & 1 & 0 & 0 & 0 & 0 \\
\hline & Ghatixalus & 4 & 0 & 0 & 0 & 0 & 0 \\
\hline Ranixalidae & Indirana & 69 & 1 & 5 & 1 & 79 & 1 \\
\hline \multirow[t]{2}{*}{ Ranidae } & Hylarana & 20 & 2 & 0 & 0 & 51 & 0 \\
\hline & Clinotarsus & 21 & 0 & 0 & 0 & 0 & 0 \\
\hline Micrixalidae & Micrixalus & 25 & 2 & 0 & 0 & 20 & 0 \\
\hline Nyctibatrachidae & Nyctibatrachus & 34 & 0 & 22 & 6 & 0 & 0 \\
\hline \multirow[t]{3}{*}{ Microhylidae } & Ramanella & 3 & 0 & 0 & 0 & 0 & 0 \\
\hline & Microhyla & 7 & 0 & 0 & 0 & 0 & 0 \\
\hline & Uperodon & 7 & 0 & 0 & 0 & 0 & 0 \\
\hline Ichthyophiidae & Ichthyophis & 3 & 0 & 0 & 0 & 0 & 0 \\
\hline \multirow[t]{2}{*}{ Indotyphlidae } & Gegeneophis & 1 & 0 & 0 & 0 & 0 & 0 \\
\hline & Unidentified juveniles and tadpoles & s 22 & 0 & 0 & 0 & 0 & 0 \\
\hline Total & & 497 & 8 & 32 & 8 & 180 & 1 \\
\hline
\end{tabular}

rate of $B d 2.4 \%$ for the entire Western Ghats. The positive samples were distributed between an altitudinal range of 300 and $1550 \mathrm{~m}$ above sea level and latitudes 8 to $20^{\circ} \mathrm{N}$ (Table 2). The prediction model suggested higher prevalence of $B d$ positives between 11 and $16^{\circ} \mathrm{N}$ (Fig. 1c), in an area with high anuran diversity, with $20 \%$ of the 170 endemic species of the Western Ghats restricted within this range.

In the current study, amphibian species belonging to 22 genera in 10 families (including 4 specimens of caecilians in 2 genera and 2 families) were sampled (Table 1). Of the total $8 B d$-positive host species (Table 2), all are endemic to the Western Ghats, except Hylarana temporalis. The 7 endemic $B d$-positive host species included shrub frogs, namely Raorchestes beddomii, R. ghatei, and Pseudophilautus amboli (Table 2). All Bd-positive host species had dilated toe- and fingertips. The higher surface area at the dilated digit tips could imply higher keratinization, which plausibly aids in harboring more zoospores (Olsen et al. 2004, Dahanukar et al. 2013). The presence of $B d$ only in amphibians with dilated digit tips is not an artifact of sampling bias, as more amphibian species without dilated digits were sampled.
Quantitative PCR detected genomic equivalents (GE) ranging from 6 to $785 B d$ zoospores for the present study with the mean GE of 126.27 (Table 2). Both of the earlier studies reported low GEs; Dahanukar et al. (2013) reported GEs ranging from 1.80 to 13.00 with a mean of 5.36, while Nair et al. (2011) reported mean GEs of 0.3 and 2.92 for the same sample. Our values of GEs are comparable, but slightly higher, to the values obtained for previous studies in Asia with the maximum reported mean $( \pm \mathrm{SE}) \mathrm{GE}$ of $325.814 \pm 107.065$ from the Philippines (Swei et al. 2011).

Genetic sequences of the $B d$-specific ITS1-5.8SITS2 ribosomal gene from the positive samples in the southern Western Ghats were identical to the sequences obtained for the northern Western Ghats by Dahanukar et al. (2013), which in turn were $100 \%$ similar to the strain obtained in Japan from the endemic amphibian Andrias japonicus (GenBank accession number AB435212) and in China from the endemic amphibian Babina pleuraden (JN870752). Our findings suggest that there is a single widespread haplotype of $B d$ in the Western Ghats, which is identical to the Asian endemic strain as argued by Dahanukar et al. (2013). 
Table 2. Host species, geographic location, and genome equivalents (GE) with standard error (SE) for Batrachochytrium dendrobatidis $(B d)$ positive samples. a.s.l.: above sea level

\begin{tabular}{|c|c|c|c|c|c|}
\hline Host species & $\begin{array}{l}\text { Latitude } \\
\left({ }^{\circ} \mathrm{N}\right)\end{array}$ & $\begin{array}{l}\text { Longitude } \\
\left({ }^{\circ} \mathrm{E}\right)\end{array}$ & $\begin{array}{l}\text { Altitude } \\
\text { (m a.s.l.) }\end{array}$ & $\begin{array}{l}\text { Mean GE } \\
\text { (SE) }\end{array}$ & Source \\
\hline Hylarana temporalis & 12.48 & 75.71 & 1149 & $222.63(79.20)$ & Present study \\
\hline Hylarana temporalis & 12.47 & 75.71 & 1131 & $57.29(2.99)$ & Present study \\
\hline Indirana brachytarsus & $8.77-9.49$ & $77.11-77.22$ & $\sim 305$ & $\begin{array}{l}\text { (a) } 2.92(3.10) \\
\text { (b) } 0.30(0.10)^{b}\end{array}$ & Nair et al. (2011) \\
\hline Indirana leithii & 19.5 & 73.7 & 1109 & $19.47(3.37)$ & Present study \\
\hline Indirana leithii & 19.39 & 73.78 & 1228 & $4.43(1.69)$ & Dahanukar et al. (2013) \\
\hline Micrixalus saxicola & 12.22 & 75.66 & 911 & $521.43(372.75)$ & Present study \\
\hline Micrixalus saxicola & 12.22 & 75.66 & 911 & $93.90(18.73)$ & Present study \\
\hline Nyctibatrachus humayuni & 19.07 & 73.54 & 853 & $6.34(3.44)$ & Dahanukar et al. (2013) \\
\hline Nyctibatrachus humayuni & 18.51 & 73.41 & 639 & $2.65(0.46)$ & Dahanukar et al. (2013) \\
\hline Nyctibatrachus humayuni & 18.52 & 73.42 & 642 & $2.12(0.28)$ & Dahanukar et al. (2013) \\
\hline Nyctibatrachus humayuni & 19.39 & 73.78 & 1228 & $5.89(3.22)$ & Dahanukar et al. (2013) \\
\hline Nyctibatrachus humayuni & 19.39 & 73.78 & 1228 & $4.11(2.46)$ & Dahanukar et al. (2013) \\
\hline Nyctibatrachus humayuni & 19.39 & 73.78 & 1228 & $11.80(1.70)$ & Dahanukar et al. (2013) \\
\hline Pseudophilautus amboli & 15.44 & 74.25 & 336 & $103.37(62.01)$ & Present study \\
\hline Raorchestes beddomii & 9.76 & 77.43 & 710 & $36.65(7.11)$ & Present study \\
\hline Raorchestes ghatei ${ }^{\mathrm{a}}$ & 19.08 & 73.54 & 975 & $7.46(1.90)$ & Present study \\
\hline Raorchestes ghatei $^{\mathrm{a}}$ & 19.07 & 73.54 & 853 & $5.6(0.01)$ & Dahanukar et al. (2013) \\
\hline
\end{tabular}

The conservation status of threatened and nonthreatened endemic amphibians of the Western Ghats may require reassessment based on the knowledge of which populations are affected by the fungal disease. The IUCN Red List of Threatened Species (IUCN 2013) identifies Pseudophilautus amboli as Critically Endangered; Indirana brachytarsus as Endangered; Micrixalus saxicola, Indirana leithii, and Nyctibatrachus humayuni as Vulnerable; and Hylarana temporalis and Raorchestes beddomii as Near Threatened. Dahanukar et al. (2013) also reported another Vulnerable species, viz. $R$. bombayensis (later identified as the newly described species, $R$. ghatei; Padhye et al. 2013). Although these species are assessed as Threatened/Near Threatened based on restricted distributions and declines in the quality of their habitat, disease impacts could potentially increase their threat status; this matter requires urgent consideration.

We show that $B d$ fungal infection is widespread within the Western Ghats and occurs on threatened and endemic anurans. Our prediction maps suggest that within the Western Ghats, the region between latitudes 11 and $16^{\circ} \mathrm{N}$ is likely to have a greater propensity for $B d$ infection. We suggest that this region be considered a hotspot of disease outbreak in need of immediate systematic surveys, conservation planning, and action. Although there is a single widespread Asian haplotype of $B d$, concurring with
Dahanukar et al. (2013), we hypothesize that the $B d$ infection is a plausible threat. This is because other anthropogenic stressors might increase the pathogenesis of $B d$ and/or decrease the immunity of the host as a result of pollution, population fragmentation, and low genetic variability imparted by population shrinkage. It is also essential to note that the current zoospore loads are slightly higher than those reported previously in the Western Ghats (Nair et al. 2011, Dahanukar et al. 2013) and Asia in general (Swei et al. 2011) which calls for continuous surveillance of the amphibian populations for $B d$.

The data obtained in our study are still in a preliminary stage; however, they do establish that the distribution of $B d$ is widespread in the Western Ghats. More systematic studies with periodic surveillance over various geographical and environmental gradients, along with laboratory studies to assess the effects of the known Asian endemic $B d$ strain, are essential to understand $B d$-host interactions in the wild and their implications in the conservation of amphibians of the Western Ghats.

Acknowledgements. The work was funded by a US Fish and Wildlife Service grant (96200-1-G275) to S.M., the Mohamed bin Zayed Species Conservation Fund (12254621) to K.K., and an INSPIRE Research Grant, Department of Science and Technology, India (IFA-LSBM-21) to N.D. We thank the Indian Institute of Science Education and 
Research (IISER), Pune, for providing infrastructural facilities. We are grateful to Allan Pessier and Asa Preston of the San Diego Zoo, Institute for Conservation Research, for helpful discussions and providing the $B d$ plasmid clones as positive controls. We thank Kevin Zippel of Amphibian Ark for helpful discussions and the Kerala, Goa, and Maharashtra state forest departments for providing the necessary permission to carry out the research. We also thank 2 anonymous reviewers for critical comments on an earlier draft of the manuscript.

\section{LITERATURE CITED}

Altschul SF, Gish W, Miller W, Myers EW, Lipman DJ (1990) Basic local alignment search tool. J Mol Biol 215:403-410

Bai C, Garner TW, Li Y (2010) First evidence of Batrachochytrium dendrobatidis in China: discovery of chytridiomycosis in introduced American bullfrogs and native amphibians in the Yunnan Province, China. EcoHealth 7: 127-134

Boyle DG, Boyle DB, Olsen V, Morgan JAT, Hyatt AD (2004) Rapid quantitative detection of chytridiomycosis (Batrachochytrium dendrobatidis) in amphibian samples using real-time Taqman PCR assay. Dis Aquat Org 60:141-148

Dahanukar N, Krutha K, Paingankar MS, Padhye AD, Modak N, Molur S (2013) Endemic Asian chytrid strain infection in threatened and endemic anurans of the northern Western Ghats, India. PLoS ONE 8:e77528

Fisher MC, Henk DA, Briggs CJ, Brownstein JS, Madoff LC, McCraw SL, Gurr SJ (2012) Emerging fungal threats to animal, plant and ecosystem health. Nature 484: 186-194.

Goka K, Yokoyama J, Une Y, Kuroki T and others (2009) Amphibian chytridiomycosis in Japan: distribution, haplotypes and possible route of entry into Japan. Mol

Editorial responsibility: Alex Hyatt,

Geelong, Victoria, Australia
Ecol 18:4757-4774

Hijmans RJ, Cameron SE, Parra JL, Jones PG, Jarvis A (2005) Very high resolution interpolated climate surfaces for global land areas. Int J Climatol 25:1965-1978

IUCN (International Union for Conservation of Nature and Natural Resources) (2013) IUCN Red List of Threatened Species. Version 2013.2. Available at www.iucnredlist. org (accessed 02 February 2014)

Molur S (2008) South Asian amphibians: taxonomy, diversity and conservation status. Int Zoo Yearb 42:143-157

Nair A, Daniel O, Gopalan SV, George S, Kumar KS, Merila J, Teacher AJF (2011) Infectious disease screening of Indirana frogs from the Western Ghats biodiversity hotspot. Herpetol Rev 42:554-557

Olsen V, Hyatt AD, Boyle DG, Mendez D (2004) Co-localisation of Batrachochytrium dendrobatidis and keratin for enhanced diagnosis of chytridiomycosis in frogs. Dis Aquat Org 61:85-88

Padhye AD, Sayyed A, Jadhav A, Dahanukar N (2013) Raorchestes ghatei, a new species of shrub frog (Anura: Rhacophoridae) from the Western Ghats of Maharashtra, India. J Threat Taxa 5:4913-4931

> Skerratt LF, Berger L, Hines HB, McDonald KR, Mendez D, Speare R (2008) Survey protocol for detecting chytridiomycosis in all Australian frog populations. Dis Aquat Org 80:85-94

> Soto-Azat C, Valenzuela-Sánchez A, Clarke BT, Busse K, Ortiz JC, Barrientos C, Cunningham AA (2013) Is chytridiomycosis driving Darwin's frogs to extinction? PLoS ONE 8:e79862

Stuart SN, Hoffmann M, Chanson JS, Cox NA, Berridge RJ, Ramani P, Young BE (2008) Threatened amphibians of the world. Lynx Edicions, Barcelona

Swei A, Rowley JJL, Rödder D, Diesmos MLL and others (2011) Is chytridiomycosis an emerging infectious disease in Asia? PLoS ONE 6:e23179

Submitted: March 17, 2014; Accepted: September 8, 2014 Proofs received from author(s): January 6, 2015 